\title{
Infantile osteopetrosis on head CT
}

\author{
Daniel Martin • Teresa Chapman
}

Received: 26 September 2008 / Revised: 16 October 2008/Accepted: 17 November 2008 / Published online: 23 December 2008

(C) Springer-Verlag 2008

An 8-month-old girl presented for evaluation of abnormal head shape and early onset of nystagmus. A noncontrast CT scan showed osseous thickening with increased sclerosis in the central aspect of the bones, most pronounced in the skull base and bilateral frontal bones, indicating osteopetrosis (Fig. 1). MRI and visual evoked potentials demonstrated optic nerve and optic chiasm atrophy (Fig. 2, arrowhead).

Blindness and deafness are seen in osteopetrosis, usually due to nerve compression by over-developing bone and narrowing optic canals (Fig. 1, arrow). A minority of cases

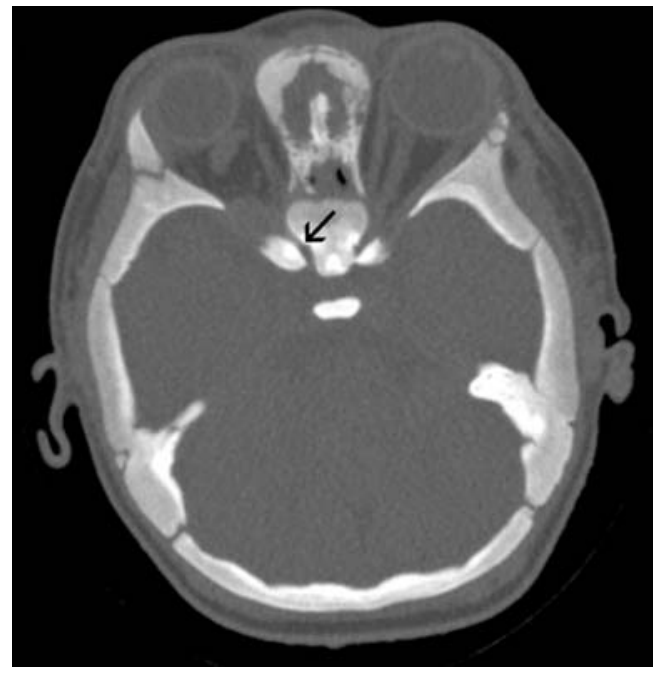

Fig. 1 Axial CT image in bone algorithm

\section{Martin}

Department of Radiology, Madigan Army Medical Center,

Tacoma, WA, USA

\section{T. Chapman $(\bowtie)$}

Department of Radiology, Seattle Children's Hospital,

4800 Sand Point Way NE, Mail Stop R-5417,

Seattle, WA 98105, USA

e-mail: teresa.chapman@seattlechildrens.org

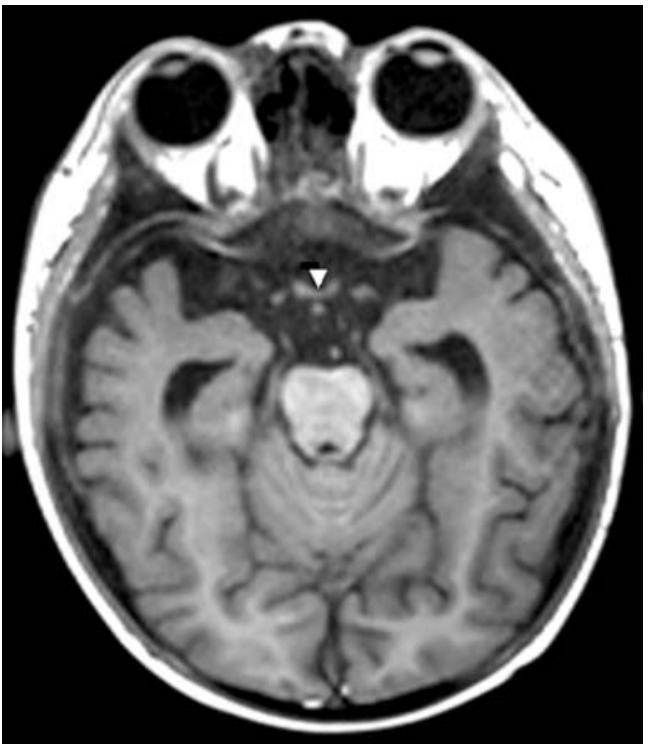

Fig. 2 Axial MR image

are due to retinal atrophy caused by lysosomal storage disease [1].

Malignant infantile osteopetrosis is often fatal, usually due to bone marrow failure and infection. Hematopoietic stem cell transplantation is performed for severe forms, although mortality remains greater than 50\% [1]. Severe neurodegeneration seen in some patients may genetically relate to a storage disorder and is a contraindication to bone marrow transplantation [2].

\section{References}

1. Del Fattore A, Cappariello A, Teti A (2008) Genetics, pathogenesis and complications of osteopetrosis. Bone 42:19-29

2. Castellano Chiodo D, DiRocco M, Gandolfo C et al (2007) Neuroimaging findings in malignant infantile osteopetrosis due to OSTM1 mutations. Neuropediatrics 38:154-156 